\title{
APPLICATION OF CLAW-POLE SYNCHRONOUS GENERATOR IN SMALL WIND TURBINES
}

\author{
Sahar Abd EImoniem Nasef, Slah Kamal, M. Kamal Ahmed and M. Zaher \\ Electrical Power and Machines Department, Faculty of Eng., Al-Azhar University, Cairo, Egypt.
}

\begin{abstract}
Small wind turbines have been in existence for several years but it seems they are not used where they are needed the most-distant off grid communities in developing countries. Cost and maintenance have been attributed to be reasons for this. One of its expensive constituents is its generator. The automotive alternator is considered as a cheaper alternative for generators in small wind turbines. In this paper, a detailed mathematical model for a 3 -phase, $4 \mathrm{~kW}$ and $42 \mathrm{~V}$ claw pole alternator average electrical equivalent circuits will be presented along with the DC/DC converter based architectures for dual-voltage systems. The performance of the $42 \mathrm{~V}$ claw pole alternator with the interleaved six-phase buck dc-to-dc converter system is modeled using Simulink software to assess the effectiveness of the model and its transient behavior.
\end{abstract}

\section{INTRODUCTION}

Many small wind turbines have been developed but market penetration has been slow or even nonexistent in developing countries because of lack of local maintenance and high cost of the product. One of the goals of this project work is to explore more affordable small wind turbines with easily accessible spare parts and maintenance. The possibility of using automotive alternators (also known as claw-pole alternators. The conventional automotive generator has a claw pole rotor with a single excitation coil wound axially. It is often named "Claw pole" alternator (Fig. 1). The excitation coil is surrounded by two solid iron pole pieces, or claw poles, and is fed via a pair of slip rings and two carbon brushes. The stator is composed of a slotted laminated iron core and a three-phase overlapped winding, wye or delta connected. It is a wavewinding in most cases.

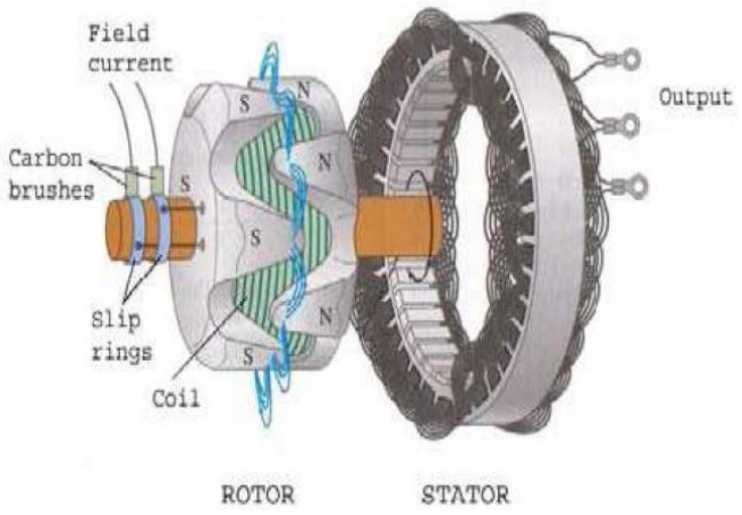

Fig. 1. Exploded view of an automotive alternator 
Its rotor is made of iron pole pieces and many turns of fine wire, which are mounted over the shaft of the machine[14]. The rotor coil leads are traced out through slip rings and brushes to the external circuit. When the rotor coils are energized, an electromagnetic field is produced. This magnetizes one set of six teeth claw poles at magnetic north and the other set at magnetic south. The stator of the alternator consists of a three-phase winding usually connected in star. The output of the stator is fed to the three-phase rectifier made of six semiconductor diodes to give a $\mathrm{DC}$ voltage and then regulated to battery voltage. The regulator begins to function when the alternator reaches cut-in speed, which is approximately $1000 \mathrm{rpm}$ at its shaft. The output voltage of the alternator increases linearly with speed if field current is maintained constant. The stator has often a single slot per pole and per phase (36 total slots). High power alternators for some applications like buses, trucks or other special vehicles have higher pole numbers (between 14 and 18). Increasing the number of poles reduces the inductance of the stator winding, and as a result, increases the short circuit current. Unfortunately the magnetic losses will also increase due to the higher electrical frequency. So the choice of pole number is actually based on a compromise between the magnetic losses and alternator power requirements. The alternator is coupled to the combustion motor through a belt. In passenger cars the maximum alternator speed (typically $8000 \mathrm{RPM}$ ) is about two times more than that of the engine crankshaft (a pulley ratio of 1:2). The Claw pole alternator is generally characterized by its form factor (a relatively large diameter compared to its length) which facilitates thermal dissipation[12].

\section{ELECTRICAL CIRCUIT}

Fig. 2 shows the simplified vehicle generation system. Usually six diodes in a full-bridge configuration are used to rectify the output current $[1,2,3]$. The rectifier is divided in two sets of three diodes. The metal casing of the first set is typically pressed into a heat sink (or welded to the heat sink) for better thermal dissipation.

The output power is controlled by regulating the field current. The regulator maintains a constant output voltage on the battery despite the varying alternator speed and variable load conditions. This voltage depends highly on the ambient temperature and the chemical characteristics of the battery and necessitates a temperature compensation by the regulator.

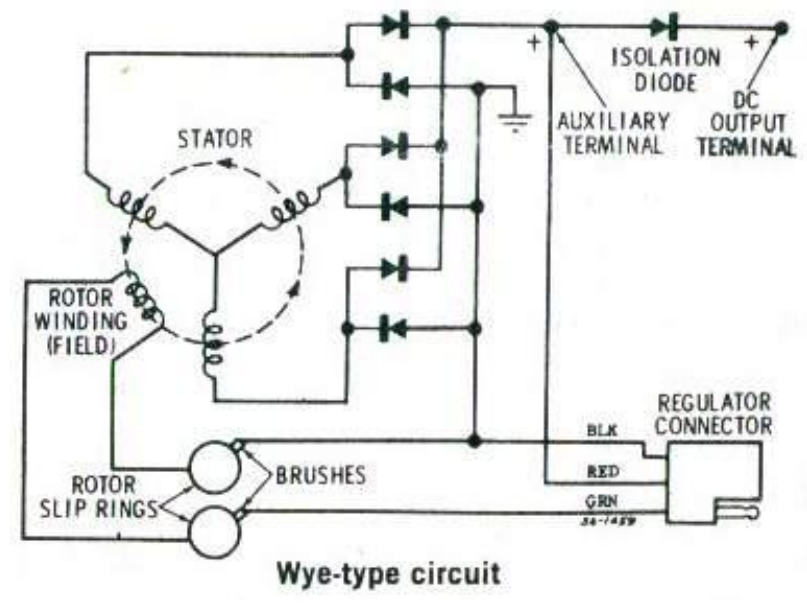

Fig. 2 Simplified vehicle generation system.

The regulator-excitation circuit is often supplied by an additional half- bridge rectifier instead of the battery (Exciter rectifier).

In the alternators with wye connected windings, two or more other auxiliary diodes are connected between the neutral point and the main rectifier output terminals. In this way it is possible to rectify the induced third harmonic voltage and increase the output current at high speeds.

\subsection{Analytical model}

The system, for a non hybrid electric passenger car with a dual-voltage electrical architecture will be discussed with more emphasis on simulation [4,5]. The proposed system is composed of a 4 
$\mathrm{kW}$ power generation system buffered by a $36 \mathrm{~V}$ energy storage battery and a $1 \mathrm{~kW}$ interleaved six-phase buck converter

The complex real-word system of three-phase coils and magneto-motive interactions to an equivalent electrical model consisting a three-phase set of back emf voltages $V_{a}, V_{b}, V_{c}$, with the leakage inductances $\mathrm{L}_{\mathrm{s}}$ and winding resistance $\mathrm{R}_{\mathrm{s}}$ in series and equipped with a field winding and brushes is shown in Figure 3.

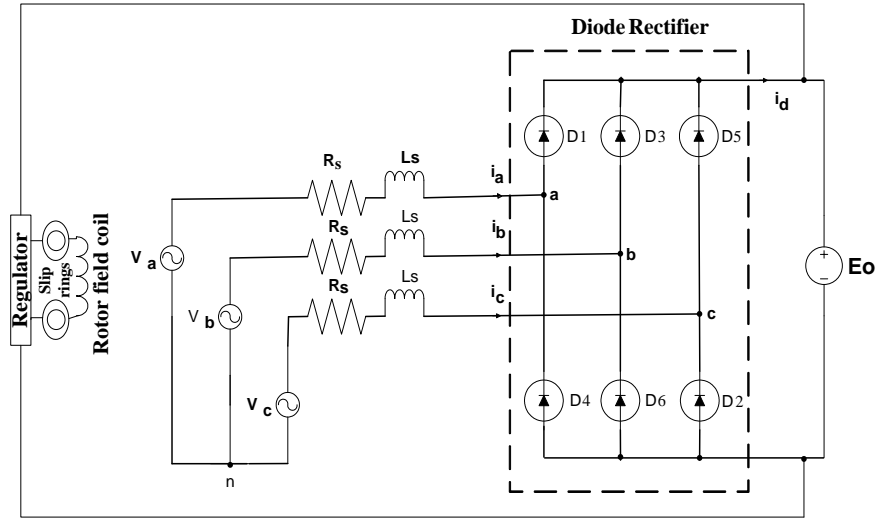

Figure 3: Electrical model of a claw pole alternator system

The output voltage of the system is controlled by regulating the machine's field excitation $i_{f}$. The electrical frequency $\omega$ is proportional to mechanical speed $\omega_{\mathrm{m}}$ and the number of machine poles. The magnitude of back emf voltage is proportional to both frequency and field current:

$$
V_{s}=K \omega i_{f}
$$

Where: $K$ is the constant of machine in $\mathrm{V}-\mathrm{s} /(\operatorname{rad}-\mathrm{A})$ and depend on the machine geometry and the winding structure.

A six-diode bridge rectifies the alternator output into constant-voltage load $\mathrm{E}_{\mathrm{o}}$ representing the battery and assisted electrical loads. For each cycle of the input voltage there are six intervals of operation of the rectifier. During each of the six intervals, only two diodes conduct with the assumption that the amount of the short period of the "overlap" is zero.

Where $\mathrm{Vg}$ is the internally generated voltage and $\mathrm{Zg}$ the total synchronous impedance and given by equation (2).

$$
\underbrace{\frac{3 \sqrt{3}}{\pi} V_{s} \cos \left(\phi-\frac{\pi}{6}\right)}_{V_{s}}=\underbrace{\left[\frac{3 R_{s}}{2}+\frac{\sqrt{3} \omega L_{s}}{2}\right]}_{Z_{g}(\omega)} \frac{3}{\pi} I_{s 1}+2 V_{d}+E_{o}
$$

Where: $V_{s}$ is the peak phase voltage, $I_{s I}$ is the magnitude of the fundamental component of the line current, and $V_{d}$ is the diode voltage drop.

The mathematical model for operational characteristics of the circuit model of the synchronous generator connected to the full-bridge diode rectifier driving a constant-voltage load [7] is derived in appendix A and its equivalent circuit model is shown in Figure 4. 


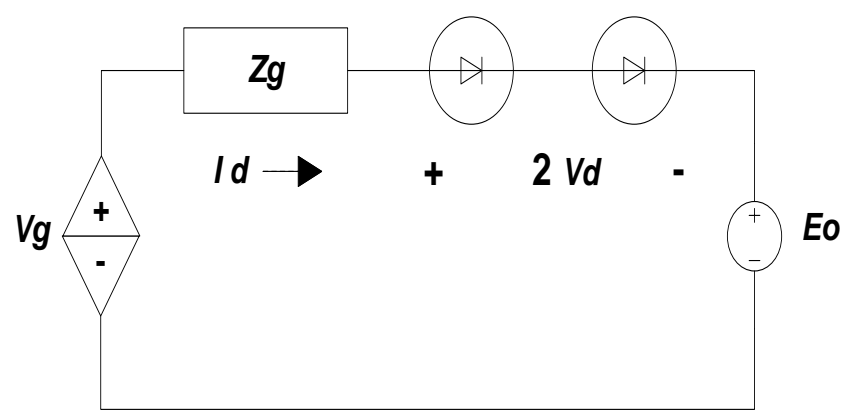

Figure 4: Synchronous generator model

Figure 5 show the six conduction intervals within each operating period for the circuit shown in Figure 3. During each of the six intervals, two of the six diodes conduct. It is sufficient to consider one of these intervals for the averaging process.

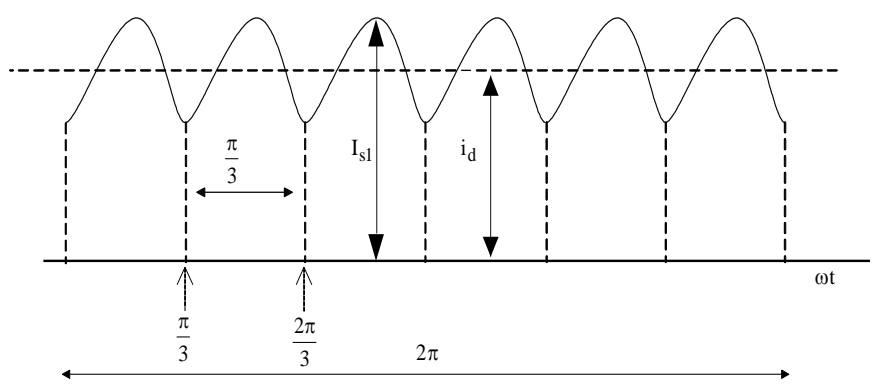

Fig. 5: A sketch of output current waveform for three-phase diode circuit

The average current delivered to the constant-voltage load Eo by the averaged equivalent circuit model is given by equation (3).

$$
i_{d}=\frac{V_{g-\left(2 V_{d}+E_{o}\right)}}{Z_{g}}
$$

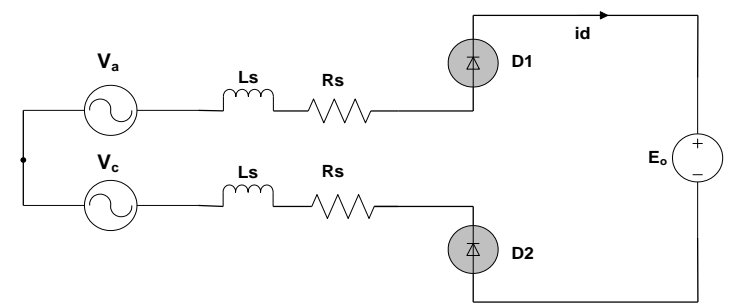

Fig. 6 The circuit diagram during the interval when diodes D1 and D2 are conducting.

Figure 6 shows three phase diode bridge rectifier equivalent circuit diagram during the interval when diode D1 and D2 conducting. Using KVL equation around a closed loop with phases a and c, diodes D1 and D2 and the voltage source $E_{o}$ gives:

$$
\begin{aligned}
V_{l l} & =V_{a}\left(\varphi \varphi-V_{c}(\varphi \varphi)\right. \\
& =L_{s} \frac{d i}{d t}+R_{s} i_{a}-L_{s} \frac{d i_{c}}{d t}-R_{s} i_{c}+2 V_{d}+E_{o}
\end{aligned}
$$

Substituting expressions of $\mathrm{v}_{\mathrm{a}}, \mathrm{v}_{\mathrm{c}}, \mathrm{i}_{\mathrm{a}}$, and $\mathrm{i}_{\mathrm{c}}$ yield the following expression: 


$$
\begin{aligned}
V_{l l} & =V_{s} \sin (\omega t)-V_{s} \sin (\omega t+2 \pi / 3) \\
& =L_{s} \frac{d\left(I_{s 1} \sin (\omega t-\phi)\right)}{d t}+R_{s}\left(I_{s 1} \sin (\omega t-\phi)\right)-L_{s} \frac{d\left(I_{s 1} \sin (\omega t-\phi+2 \pi / 3)\right)}{d t}-R_{s}\left(I_{s 1} \sin (\omega t-\phi+2 \pi / 3)\right)+2 V_{d}+E_{o} \\
V_{l l} & =\sqrt{3} V_{s} \sin (\omega t-\pi / 6) \\
& =I_{s 1}\left[L_{s} \omega \cos (\omega t-\phi)+R_{s} \sin (\omega t-\phi)\right]-I_{s 1}\left[L_{s} \omega \cos (\omega t-\phi+2 \pi / 3)+R_{s} \sin (\omega t-\phi+2 \pi / 3)\right]+2 V_{d}+E_{0}
\end{aligned}
$$

Where: $\mathrm{a}=\mathrm{L}_{\mathrm{S}} \omega, \quad \mathrm{b}=\mathrm{R}_{\mathrm{S}}$

$\sqrt{3} V_{s} \sin (\omega t-\pi / 6)=I_{s 1}[a \cos (\omega t-\phi)+b \sin (\omega t-\phi)]-I_{s 1}[a \cos (\omega t-\phi+2 \pi / 3)+b \sin (\omega t-\phi+2 \pi / 3)]+2 V_{d}+E_{o}$

Applying the Trigonometric Identity :

$a \cos \phi+b \sin \phi=A \cos (\phi-\alpha)$

Where: $\quad \mathrm{A}=\sqrt{\mathrm{a}^{2}+\mathrm{b}^{2}}, \quad \alpha=\tan ^{-1}(\mathrm{~b} / \mathrm{a})$ on the right hand side of equation (4)

$V_{l l}=\sqrt{3} V_{s} \sin (\omega t-\pi / 6)$

$=I_{s 1}[A \cos (\omega t-\phi-\alpha)]-I_{s 1}[A \cos (\omega t-\phi+2 \pi / 3-\alpha)]+2 V_{d}+E_{o}$

$V_{l l}=A I_{s 1} \cos (\omega t-\phi-\alpha)-A I_{s 1} \cos (\omega t-\phi+2 \pi / 3-\alpha)+2 V_{d}+E_{o}$

First, averaging the left hand side of the eq. (5) over a conduction angle of $\frac{\pi}{3}$.

$$
\begin{aligned}
& \frac{3 \sqrt{3}}{\pi} V_{s} \int_{\phi+\pi / 3}^{\phi+2 \pi / 3} \sin (\omega t-\pi / 6) d(\omega t) \\
& =\frac{3 \sqrt{3}}{\pi} V_{s}[-\cos (\omega t-\pi / 6)]_{\phi+\pi / 3}^{\phi+2 \pi / 3} \\
& =\frac{3 \sqrt{3}}{\pi} V_{s}\left[\cos \left(\phi+\frac{\pi}{6}\right)-\cos \left(\phi+\frac{\pi}{2}\right)\right] \\
& =\frac{3 \sqrt{3}}{\pi} V_{s}\left[\frac{\sqrt{3}}{2} \cos \phi+\frac{1}{2} \sin \phi\right] \\
& =\frac{3 \sqrt{3}}{\pi} V_{s} \cos \left(\phi-\frac{\pi}{6}\right)
\end{aligned}
$$

Now, averaging the right hand side of equation (7)

$$
\begin{aligned}
& \frac{3}{\pi} \int_{\phi+\pi / 3}^{\phi+2 \pi / 3}\left[A I_{s 1}\left[\cos (\omega t-\phi-\alpha)-\cos \left(\omega t-\phi+\frac{2 \pi}{3}-\alpha\right)+2 V_{d}+E_{o}\right]\right] d(\omega t) \\
& =\frac{3}{\pi} A I_{s 1} \int_{\phi+\pi / 3}^{\phi+2 \pi / 3} \cos (\omega t-\phi-\alpha) d(\omega t)-\frac{3}{\pi} A I_{s 1} \int_{\phi+\pi / 3}^{\phi+2 \pi / 3} \cos \left(\omega t-\phi+\frac{2 \pi}{3}-\alpha\right) d(\omega t)+2 V_{d}+E_{o}
\end{aligned}
$$




$$
\begin{aligned}
& =\frac{3}{\pi} A I_{s 1}[\sin (\omega t-\phi-\alpha)]_{\phi+\pi / 3}^{\phi+2 \pi / 3}-\frac{3}{\pi} A I_{s 1}\left[\sin \left(\omega t-\phi+\frac{2 \pi}{3}-\alpha\right)\right]_{\phi+\pi / 3}^{\phi+2 \pi / 3}+2 V_{d}+E_{o} \\
& =\frac{3}{\pi} A I_{s 1}\left[\sin \left(\frac{2 \pi}{3}-\alpha\right)-\sin \left(\frac{\pi}{3}-\alpha\right)\right]-\frac{3}{\pi} A I_{s 1}\left[\sin \left(\frac{4 \pi}{3}-\alpha\right)-\sin (\pi-\alpha)\right]+2 V_{d}+E_{o} \\
& =\frac{3}{\pi} A I_{s 1}\left[\sin \alpha+\frac{1}{2}(\sqrt{3} \cos \alpha+\sin \alpha)\right]+2 V_{d}+E_{o} \\
& =\frac{3}{\pi} A I_{s 1}\left[\frac{3}{2} \sin \alpha+\frac{\sqrt{3}}{2} \cos \alpha\right]+2 V_{d}+E_{o} \\
& V_{g}=\frac{3 \sqrt{3}}{\pi} V_{s} \cos \left(\phi-\frac{\pi}{6}\right) \\
& Z_{g}=\frac{3 R_{s}}{2}+\frac{\sqrt{3} \omega L_{s}}{2}
\end{aligned}
$$

Refer to (figure 2), $I_{d}$ can be calculated as follows

$$
\begin{aligned}
I_{d} & =\frac{1}{T} \int_{\pi / 3}^{2 \pi / 3} f(\theta) d \theta \\
& =\frac{3}{\pi} \int_{\pi / 3}^{2 \pi / 3} I_{s 1} \sin \theta d \theta \\
& =-\left.\frac{3}{\pi} I_{s 1} \cos \theta\right|_{\pi / 3} ^{2 \pi / 3} \\
& =\frac{3}{\pi} I_{s 1}\left[\cos \frac{\pi}{3}-\cos \frac{2 \pi}{3}\right]=\frac{3}{\pi} I_{s 1}
\end{aligned}
$$

The average current delivered to the load by the averaged circuit model is:

$$
I_{d}=\frac{V_{g}-\left(2 V_{d}+E_{0}\right)}{Z_{g}}
$$

\subsection{Alternators Electrical Behaviour}

Equations (1 and 2) are used to simulate the alternator averaged model using Matlab software, with the $14 \mathrm{~V}$ and $42 \mathrm{~V}$ Claw pole alternator machine's parameters shown in Table 2. In addition a Simulink block diagram was created using the input parameters to produce the desired output simulation results, as shown in Figure 5.

Table 2: 14V and 42V Claw pole Alternator Parameters.

\begin{tabular}{|l|l|l|l|}
\hline Parameters & Description & $14 \mathrm{~V}$ & $42 \mathrm{~V}$ \\
\hline Rs (Ohms) & $\begin{array}{l}\text { Stator winding } \\
\text { resistance }\end{array}$ & $33 \mathrm{e}-3$ & $133.65 \mathrm{e}-3$ \\
\hline ( Henries $)$ & $\begin{array}{l}\text { Stator leakage } \\
\text { inductance }\end{array}$ & $166 \mathrm{e}-6$ & $0.729 \mathrm{e}-3$ \\
\hline$V d$ (Volts $)$ & Diode drops & 1 & 1 \\
\hline$I f($ Ampers $)$ & Field current & 3.6 & 3.6 \\
\hline$k$ & Machine constant & $4.2867 \mathrm{e}-3$ & $1.286 \mathrm{e}-2$ \\
\hline$r p m$ & Alternator speed & $700: 1800$ & $700: 1800$ \\
\hline$p$ & Number of poles & 12 & 12 \\
\hline Eo (Volts) & $\begin{array}{l}\text { Alternator } \\
\text { voltage }\end{array}$ & 14 & 42 \\
\hline & & & \\
\hline
\end{tabular}


Figure 6 shows the performance curve for the present $14 \mathrm{~V}$ automotive alternator which is capable of supplying approximately $93 \mathrm{~A}$ of dc current at an alternator speed of $1800 \mathrm{rpm}$ (ideal speed). As the alternator speed increases the maximum output dc current is about $124 \mathrm{~A}$ at cruising speed $(6000 \mathrm{rpm})$. For comparison the average alternator data for the Bosch NC $14 \mathrm{~V}$ 60-120 A model is plotted which shows a good agreement between the developed model and the real characteristic of the machine. As can be seen, the present alternator is capable of supplying approximately 97A of D.C. current at ideal speed $(1800 \mathrm{rpm})$. This low speed situation represents a car stationary and the engine idling during traffic in cities, which is becoming more severe with the increase in car population. The electrical power level delivered is reduced and the alternator cannot provide adequate current. In this case, the alternator, cooperate with battery, over a period of time, to compensate for the temporary imbalance. The corresponding power approximately is $1.4 \mathrm{~kW}$. As the alternator speed increases the output dc current is about $135 \mathrm{~A}$ at cruising speed $(6000 \mathrm{rpm})$ while the power increases approximately to $1.7 \mathrm{~kW}$ which represents a car cruising at higher engine speed. The alternators supply the electrical loads with energy and recharge the battery without the problem of over charge. Other scenario are parking demand and starting demand. However, there are always losses when converting mechanical energy to electrical energy. A normally operated alternator has an average efficiency of 50\% and decreases at higher speeds. The losses are related to iron losses (hysteresis and eddy currents), copper losses, friction and aerodynamic losses [5, 9]. The relatively high losses are compensated by the lightweight, compact design and low investments costs. This 1.4-1.7 kW system is incapable of handling high power electric loads to be introduced in the future cars and it would be expensive and inefficient to do so. To meet the future electrical power demands, $42 \mathrm{~V}$ automotive power generators are becoming necessary. As illustrated in Figure 7, the 42V alternator is capable of supplying 71A of D.C. current at ideal speed. As the alternator speed increases the output D.C. current is about 95A (cruising speed). The machine is capable generating approximately $3 \mathrm{kWat}$ idle, but power capability increases to $4 \mathrm{~kW}$ at cruising speed of.

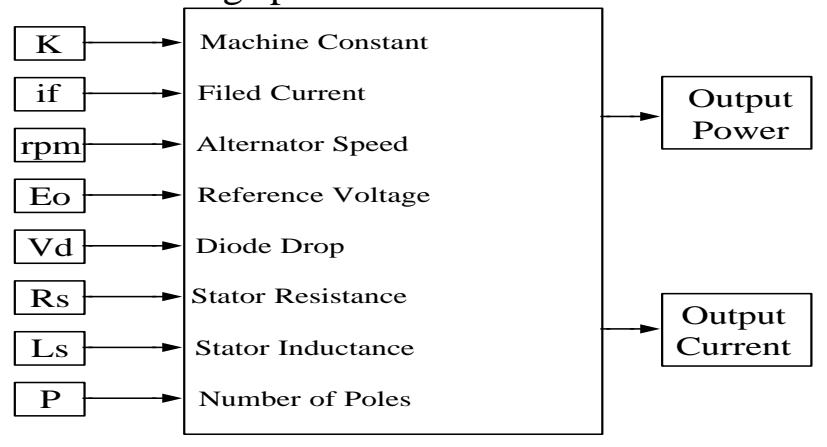

Fig. 5. Simulink functional model of the Alternator 
Performance Curve for $1.7 \mathrm{~kW} / 14 \mathrm{~V}$ Alternator

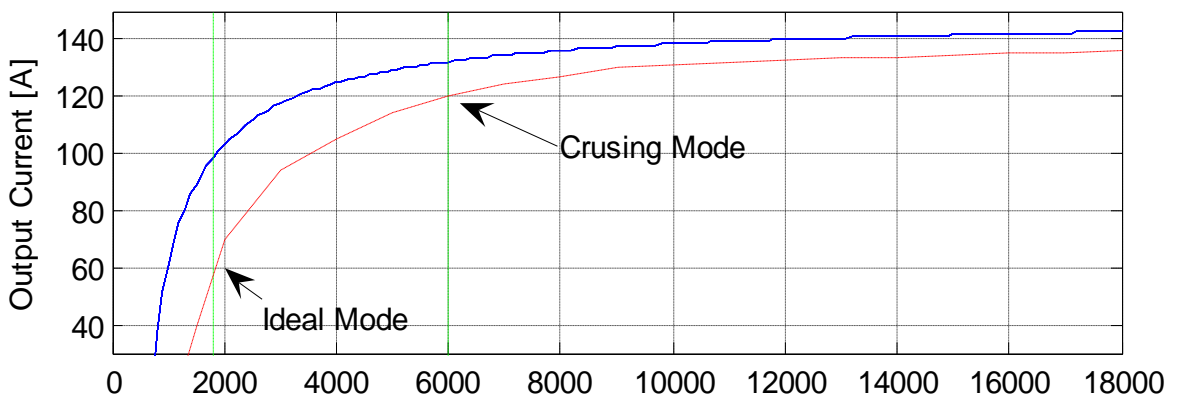

Output Power for 14V alternator

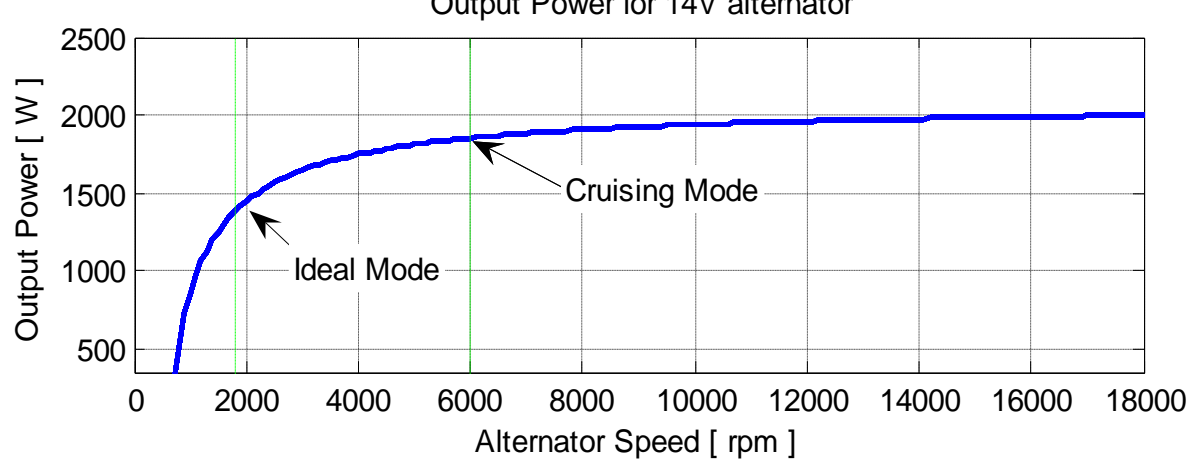

Figure 6: Performance curve and output power for $14 \mathrm{~V}$
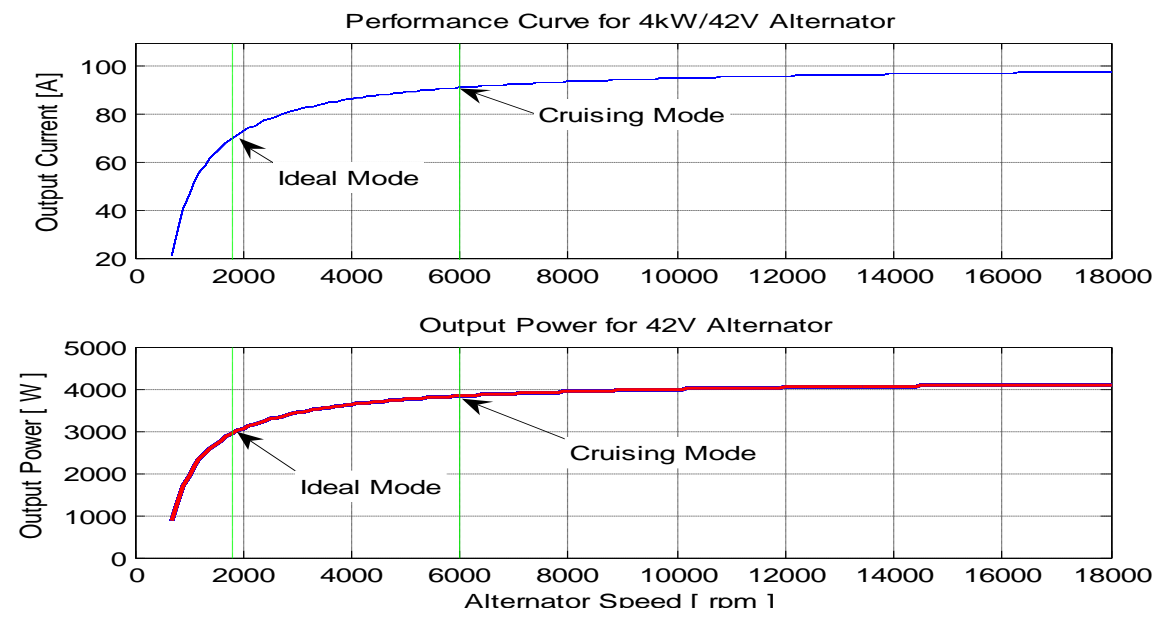

Figure 7: Performance curve and output power for a $42 \mathrm{~V}$ alternator

\section{SIMULATION RESULTS}

Figure 8 shows the simulated results of the two buses at different level of voltages and powers. The high voltage deliver $3 \mathrm{~kW}$ at an average output current of $71 \mathrm{~A}$, while the voltage, $14 \mathrm{~V}$ bus, delivers a current of $71 \mathrm{~A}$ at $1 \mathrm{~kW}$. The simulation results illustrate that, the operation of the complete system is stable and accurate. The system is able to respond and produce the desired output voltages and required level of currents. 

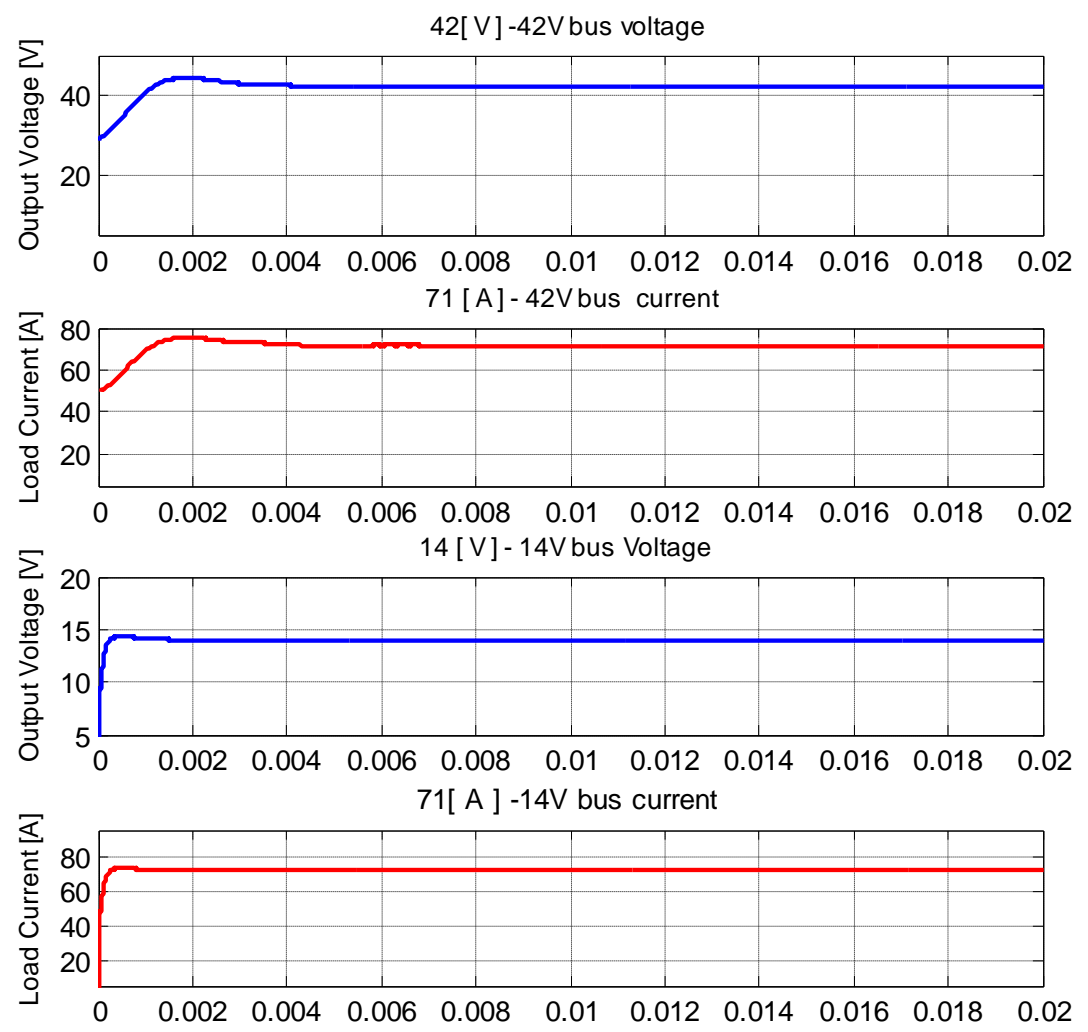

Figure 8: Voltage and current of the two buses

\section{CONCLUSION}

It can be concluded from the results obtained that the dc-dc based architecture system is a potential solution for a more efficient and stable automotive electrical power system. The system complies with the demanding requirements of the automotive industry in terms of current and voltage surges. It is anticipated that the system proposed here will be of value in future dualvoltage automotive electrical systems

\section{REFERENCES}

1. J.Abu-Qahouq, H. Mao and I. Batarseh. "Multiphase Voltage-Mode Hysteretic Controlled DC-DC Converter with Novel Current Sharing", IEEE Transactions on Power Electronics, volume19, No.6, pp.1397-1407.Novmber, (2004).

2. K. H. Ang, G.Chong, and Y. Li. "PID Control System Analysis, Design, and Technology", IEEE Transaction on Control Systems Technology, volume.13, No. 4, JULY, (2005).

3. J.Aikalay,H,Kendall,M.Laskowski,A.Lee, and D.Noderer. "Survey o Conducted Transients in the Electrical System of a Passenger Automobile", IEEE International Symposium on Electromagnetic Compatibility, Denver Co, (1989).

4. J.M.Altes ,E.G. Dolcet, and B.P. Solorzano. "Analysis of the Most Appropriate Electrical Architecture and Communication Bus for the New Dual Voltage 14/42v System", IECON-2002: Proceedings of the 2002 28th Annual Conference of the IEEE Industrial Electronics Society, volumes 1-4 ,pp. 1687-1692, (2002).

5. K.Bolenz and W.Schleuter. "Design Modifications of Alternator, Starter and Battery to Reduce Fuel Consumption.", Proceedings of the International Congress on Transportation Electronics; pp.355-362, Dearborn, MI, USA, October, (1994). 
6. J. C. Byrum. "Comparative evaluation of dual-voltage automotive alternators", Laboratory for Electromagnetic and Electronic Systems (LEES), Cambridge, Tech. Rep.TR-00-012, November (2000)

7. V.Caliskan, D.J. Perreault, T.M. Jahns, and J.G. Kassakian. "Analysis of Three- Phase Rectifiers With Constant-Voltage Loads", IEEE Transaction on Circuitsand System-I: Fundamental Theory and Applications, volume50, No.9, pp.12201-226, September (2003).

8. V.Caliskan. "Design and Analysis of Dual/High Voltage Automotive Electrical Power System Architectures", Ph.D. thesis, Massachusetts Institute of Technology, Department of Electrical Engineering and Computer Science, (200).

9. E. Ceuca, R. Joldes, E. Olteanu, "Simulation of automotive alternator - solution for increasing electrical power", Proceeding of 2006 IEEE - The International Conference on Automation, Quality and Testing, Robotics, Cluj-Napoca, May 2006, vol 1, pp 292-297.

10. A.Emadi, S.S.Williamson, and A. Khaligh. "Power Electronics Intensive Solutions for Advanced Electric, Hybrid Electric, and Fuel Cell Vehicular Power Systems", IEEE Transactions on Power Electronics, volume.21. No.3, May, (2006).

11. Barz C., Oprea, C., "Contribution to the tridimensional analysis of electromagnetic field in claw poles alternator", Journal of Electrical and Electronics Engineering, Vol. 3, Nr. 1, ISSN1844-6035 (B+), pg. 29-34, Oradea, 2010

12. Komeza, Krzysztof, Dems, and Maria, "Magneto-thermal analysis of a high-speed claw pole motor considering rotational core loss," IEEE Trans. Industrial Electronics, Vol. 59, pp. 2934-2946, 2012.

13. Proefschrift: "Low Cost Small Wind Turbine Generators for Developing Countries", Master Thesis (Electrical Engineering), University of Nigeria, NsukkageborenteIkem, Nigeria.(2013).

14. Su Pwint Phyo and Thet Htun Aung "Wind Turbine Generation System Implemented with a Claw Pole Alternator" International Journal of Scientific Engineering and Technology Research Volume.03, IssueNo.16, July-2014, Pages: 3411-3416 